\title{
Pendidikan Alquran (TPQ) Sebagai Upaya Membentuk Karakter Pada Anak
}

\author{
Rosyida Nurul Anwar \\ Universitas PGRI Madiun \\ Email: Rosyidanurul@unipma.ac.id
}

\begin{abstract}
Abstrak
Pendidikan dipandang sebagai proses belajar sepanjang hayat manusia. Fungsi pendidikan nasional untuk membentuk watak peradaban bangsa yang bermartabat dan mengembangkan kemampuan untuk mencerdaskan kehidupan bangsa. Taman Pendidikan Al Quran (TPQ) Anwarul Qulub merupakan lembaga non formal yang menyelenggarakan pendidikan al Quran dalam upaya pembentukan karakter di lingkungan Sidorejo Desa Sidomulyo Kecamatan Sawahan Kabupaten Madiun. Tujuan penelitian ini adalah untuk mengetahui pelaksanaan program pendidikan TPQ Anwarul Qulub dalam rangka penanaman pendidikan karakter anak di lingkungan Sidorejo, hambatan dalam pelaksanaan program TPQ Anwarul Qulub dan cara mengatasi berbagai hambatan yang ada selama pelaksanaan program pendidikan tersebut. Penelitian ini menggunakan jenis kualitatif deskriptif. Teknik pengumpulan data dilakukan dengan cara observasi, wawancara, dan dokumentasi. Temuan penelitian menunjukkan bahwa program dilaksanakan dalam upaya pendidikan karakter melalui pengajaran bacaan Al Quran secara mendalam, penghafalan surat-surat juz amma, penafsiran ayat Al Quran, hadist dan kata-kata mutiara berbahasa arab (Mahfuzhat). Hambatan dalam pelaksanaan yakni banyaknya jumlah peserta didik dan keterbatasan guru yang mengajar. Cara mengatasi hambatan membiarkan anak belajar sambil bermain namun tetap pada pengawasan dan pembimbingan guru. Pendidikan Al Quran memiliki peranan penting dalam membentuk karakter santri melalui pembimbingan, melatih secara terus menerus dan menasehati dalam membentuk karakter religius, mandiri, serta komunikatif pada anak usia dini.
\end{abstract}

Kata Kunci: pendidikan al Quran, pendidikan karakter, anak usia dini

\begin{abstract}
Education is seen as a lifelong learning process. The function of national education is to shape the dignified character of the nation's civilization and develop the ability to educate the nation's life. Anwarul Qulub Al Quran Education Park (TPQ) is a non-formal institution that organizes Al-Quran education to build character in the Sidorejo neighborhood, Sidomulyo Village, Sawahan District, Madiun Regency. The purpose of this study was to determine the implementation of the TPQ Anwarul Qulub education program in the context of cultivating children's character education in the Sidorejo environment, obstacles in the implementation of the Anwarul Qulub TPQ program, and how to overcome various obstacles that existed during the implementation of the education program. This research uses descriptive qualitative type. The data collection technique was done using observation, interviews, and documentation. The research findings show that the program is implemented in the effort of character education through teaching in-depth Al-Quran reading, memorizing juz amma letters, interpreting Al-Quran verses, hadiths, and Arabic aphorisms (Mahfuzhat). Barriers to implementation are a large number of students and the limited number of teachers who teach. How to overcome obstacles to let children learn while playing but still under teacher supervision and guidance. Al-Quran education has an important role in shaping the character of students through mentoring, continuous training, and advice in shaping religious, independent, and communicative characters in early childhood.
\end{abstract}

Keywords: al Quran education, character education, early childhood 


\section{PENDAHULUAN}

Memasuki abad 21 banyak pendidik dan orangtua pada lembaga penyelenggara pendidikan ingin menekankan hadirnya kembali pendidikan budi pekerti (Herman, 2018). Seorang anak telah menjadi pasar baru dari kuatnya produksi informasi dari dunia maya. (Iswan \& Herwina, 2018). Fenomena ini menjadi sebuah gagasan karakter anak harus dihidupkan kembali dan ditingkatkan. Mengenalkan kembali nilai-nilai positif bagi anak-anak dan remaja dalam kaitannya dengan maraknya perilaku kejahatan dan kekerasan dalam masyarakat.

Kondisi moral dan akhlak generasi dinodai dengan hilangnya karakter sebagai pribadi yang memegang nilai-nilai kedudukan pancasila. Sebagai contoh kelalaian dalam melaksanakan ibadah kepada Tuhan yang Maha Esa, hilangnya rasa kemanusiaan ditandai dengan maraknya pembunuhan yang terjadi diantara masyarakat, kurangnya rasa persatuan seperti terjadinya tawuran antar pelajar, tawuran antar suku dan golongan, maraknya kasus korupsi yang dilakukan oleh pihak-pihak pemangku kebijakan negara, dan hilangnya rasa keadilan sosial seperti terjadinya suap dalam proses penyeleksian sebuah kompetisi baik yang dilakukan secara personal maupun lembaga pemerintahan (Anwar, Wardani, \& Vitriana, 2019). Terjadinya degradasi pengetahuan dan dekadensi akhlak yang sudah akut menjakiti bangsa Indonesia disemua kalangan masyarakat,

termasuk kalangan pelajar menyebabkan pendidikan karakter menjadi sebuah kebutuhan mendesak (Asmani, 2012).

Menurut harlock dalam bukunya personality development dalam Warsito karakter terletak pada kepribadian (Warsito, 2014). Karakter mengimplikasikan pada standar moral yang melibatkan sebuah perimbangan nilai, karakter berkaitan dengan tingkah laku yang diatur oleh upaya dan keinginan. Dewasa ini anak-anak mengalami kemunduran moral dan etika atau degradasi moral seperti kasus pelecehan seksual yang melibatkan siswa kelas empat Sekolah Dasar (SD), tindakan pemukulan yang dilakukan anak
Sekolah Menengah Pertama (SMP) kepada gurunya bahkan mengakibatkan guru tersebut kehilangan nyawa, anak SD yang berani membully temannya bahkan mengambil barang yang bukan menjadi haknya. Krisis moral saat ini mensyaratkan untuk segera dilakukannya rediscovery nilai-nilai luhur budaya bangsa. Nilai-nilai baik yang diwujudkan dalam bentuk perilaku disebut dengan karakter. Suatu karakter melekat dengan nilai dari perilaku tersebut, oleh karenanya tidak ada perilaku anak yang tidak bebas dari nilai.

Dalam perspektif Islam, nilai perilaku atau akhlak tercermin pada Nabi Muhammad yaitu; amanah, tabligh, sidik, dan fatonah. Ratna Megawangi dalam buku Character Parenting Space yang dikutip oleh Dalmeri, ada beberapa karakter yang harus diturunkan dan diabadikan, yaitu; pertama, cinta kepada Tuhan Yang Maha Esa dan kebenaran; kedua, tanggung jawab, kedisiplinan dan kemandirian; ketiga, amanah; keempat, hormat dan santun; kelima, kasih sayang, kepedulian dan kerjasama; keenam, percaya diri, kreatif dan pantang menyerah; ketujuh, keadilan dan kepemimpinan; kedelapan, baik dan rendah hati; dan kesembilan, toleransi dan cinta damai, kesemuanya tersebut dinamakan sembilan pilar pendidikan karakter (Dalmeri, 2014). Pendidikan karakter sebagai proses pemberian tuntunan kepada peserta didik untuk mengembangkan sikap dan perilaku secara optimal dan menyeluruh. Sasaran pendidikan karakter adalah seluruh warga sivitas akademika yang terdapat pada setiap satuan pendidikan, baik formal, informal maupun non formal (Setiardi, 2017).

Satuan pendidikan non formal terdiri dari lembaga kursus, lembaga pelatihan, kelompok belajar, pusat kegiatan belajar masyarakat, pendidikan keagamaan dan satuan pendidikan yang sejenis (Anwar, 2019). Kurikulumnya yang diterapkan pada TPQ setara dengan taman kanakkanak (TK) dan RA yaitu menekankan pada pemberian dasar-dasar membaca Al Qur'an serta membantu pertumbuhan dan perkembangan rohani anak agar memiliki kesiapan dalam memasuki pendidikan lebih lanjut. Terselenggarannya pendidikan nonformal dalam bentuk Taman 
Pendidikan Al Quran (TPQ) sebagai lembaga pendidikan Islam merupakan peluang bagi terbentuknya karakter melalui pendidikan karakter yang melibatkan seluruh komponen pendidikan pada anak. Pada penerapannya, banyak TPQ yang berlomba-lomba dalam mewujudkan TPQ yang menekankan pendidikan karakter didalamnya. TPQ Anwarul Qulub adalah lembaga pendidikan nonformal yang terletak di Dusun Sidorejo Desa Sidomulyo Kecamatan Sawahan Kabupaten Madiun. Upaya pendidikan karakter yang ada pada TPQ Anwarul Qulub melibatkan seluruh komponen pendidikan dalam menjalankan proses interaksi kepada peserta didik dalam upaya mewujudkan karakter dan akhlak yang sesuai dengan tuntunan Islam dikesehariannya.

Berdasarkan latar belakang yang telah peneliti uraikan, maka fokus penelitian ini adalah; 1) bagaimana pelaksanaan program pendidikan dalam upaya mewujudkan pendidikan karakter anak pada TPQ Anwarul Qulub? 2) bagaimana hambatan dalam pelaksanaan program pendidikan dalam upaya mewujudkan pendidikan karakter anak pada TPQ Anwarul Qulub, dan 3) bagaimana cara mengatasi hambatan yang ada dalam upaya mewujudkan pendidikan karakter anak pada TPQ Anwarul Qulub.

Tujuan pada penelitian ini adalah; 1) untuk mengetahui program pendidikan dalam upaya mewujudkan pendidikan karakter anak pada TPQ Anwarul Qulub; 2) untuk mengetahui hambatan dalam pelaksanaan program pendidikan dalam upaya mewujudkan pendidikan karakter anak pada TPQ Anwarul Qulub, dan 3) untuk mengetahui cara mengatasi hambatan yang ada dalam upaya mewujudkan pendidikan karakter anak pada TPQ Anwarul Qulub. Secara teoritis, manfaat pada penelitian ini adalah untuk memberikan sumbangan pemikiran dalam ilmu pengetahuan serta memperkaya konsep-konsep dan teori-teori pada ilmu pengetahuan. Sedangkan secara praktis penelitian ini diharapkan mampu memberikan pengalaman serta wawasan bagi peneliti sendiri dan bagi peneliti selanjutnya serta sebagai acuan bagi penyelenggaraan pendidikan non formal secara umum dan TPQ Anwarul Qulub secara khusus.

\section{METODOLOGI PENELITIAN}

Penelitian ini menggunakan jenis penelitian deskriptif dengan pendekatan kualitatif. Tempat penelitian ditentukan dengan teknik Purposive Area, yaitu pada pendidikan non formal yaitu Taman Pendididikan Al Quran (TPQ) Anwarul Qulub di Dusun Sidorejo Desa Sidomulyo Kecamatan Sawahan Kabupaten Madiun. Teknik penentuan informan dalam penelitian ini menggunakan teknik Purposive Sampling, dan teknik penentuan Informan menggunakan teknik Snowball Sampling. Dengan Informan kunci yaitu Pendidik dan santri serta Informan pendukung yaitu orang tua santri. Teknik pengumpulan data dilakukan dengan cara observasi, wawancara, dan dokumentasi. Teknik pengolahan data yakni menggunakan perpanjangan penelitian, peningkatan ketekunan, dan triangulasi menggunakan triangulasi sumber dan teknik. Analisis data dilakukan dengan menggunakan analisis model Miles dan Huberman yakni pengumpulan data, reduksi data, penyajian data, dan penarikan kesimpulan.

\section{HASIL PENELITIAN DAN PEMBAHASAN}

\section{Pelaksanaan Pendidikan Al Quran Dalam Upaya Membentuk Karakter Anak}

Hasil pada penelitian ini menunjukkan bahwa pelaksanaan program pendidikan dalam upaya mewujudkan pendidikan karakter anak pada TPQ Anwarul Qulub adalah: Pertama, mengajarkan anak untuk membaca Al Quran secara mendalam, yaitu dengan mendetail, terperinci dan terus menerus. Dalam hal ini pendidik pada TPQ Anwarul Qulub membimbing peserta didik untuk lancar membaca Al Quran ditunjukkan dengan mahir dalam makhrajil huruf, tajwid, dan tidak akan naik pada tingkatan selanjutnya sebelum melalui penilaian dalam bentuk test lisan membaca Iqra'. Pada proses pembimbingan membaca Al Quran tersebut anak dilatih untuk bersabar untuk tidak naik tingkatan membaca Iqra' apabila belum mahir. Dengan kesabaran yang dilatih secara terus- 
menerus anak terbiasa untuk bertanggunggjawab atas dirinya sendiri, dilatih untuk mengendalikan emosi, dilatih untuk berusaha menggapai prestasi dengan usahanya sendiri dan bukan karena rasa empati yang dimiliki oleh guru. Program pengajaran Al Quran secara mendalam oleh TPQ Anwarul Qulub dalam kaitan membentuk karakter mengakibatkan anak memiliki kepribadian positif diluar TPQ seperti sabarnya anak ketika dirumah apabila diminta tolong oleh orangtua atau anggota keluarga yang lain dirumah, usaha mendapatkan juara pertama disekolah dengan rajin membaca dan memperhatikan guru di sekolah serta tidak bermain-main pada kegiatan yang merugikan orang lain contohnya mencontek, tindakan bullying, dan berbicara dengan teman saat pembelajaran berlangsung.

Kedua, memberikan hafalan surat-surat pendek (juz amma) kepada anak, melalui hafalan yang diberikan kepada peserta didik, anak yang belum mahir membaca Al Quran akan diisi dengan menghafal surat-surat pendek yang ada dlam Al Quran tanpa harus bisa membaca $\mathrm{Al}$ Quran terlebih dahulu. Metode yang dipakai oleh pendidik pada TPQ dalam memberikan hafalan kepada anak adalah dengan mengulang-ngulang bacaan yang diberikan kepadanya dan tidak bisa menghafalkan surat berikutnya sebelum hafal pada surat yang sedang dihafal tersebut. Ketika anak telah mampu menghafalkan surat juz amma tersebut, setelahnya diperbaiki bacaan Al Quran yang belum sesuai dengan tajwid ataupun mahkrajil hurufnya. Program menghafal dengan terus-menerus secara tidak langsung berimplikasi kepada tindakan anak untuk bersungguh-sungguh dalam berbuat kebaikan.

Ketiga, memberikan materi tentang tafsir ayat Al Quran, hadist dan kata-kata mutiara berbahasa arab (Mahfuzhat). Pada saat program ini berlangsung, pendidik terbiasa memberikan penjelasan secara detail mengenai ayat-ayat $\mathrm{Al}$ Quran, hadits dan mahfuzhat dengan menyisipkan nasehat daan relevansinya terhadap kehidupan sehari-hari terutama ketika anak di posisikan sebagai seorang anggota keluarga, sebagai murid pada sebuah pendidikan dan sebagai masyarakat pada lingkungan. Nasehat yang sampaikan dapat membentuk kepribadian dan karakter anak dibuktikan dengan melaksanan apa yang dperintahkan dan menjauhi larangan yang terdapat pada Al Quran sesuai dengan syariat Islam.

\section{Hambatan Pendidikan Al Quran Dalam Upaya Membentuk Karakter Anak}

Hambatan dalam pelaksanaan program pendidikan dalam upaya mewujudkan pendidikan karakter anak pada TPQ Anwarul Qulub adalah banyaknya peserta didik yang mengikuti proses pembelajaran di TPQ sedangkan jumlah guru sangat terbatas. Jumlah anak yang melebihi kuota menjadikan proses pembentukan karakter anak menjadi tidak maksimal. TPQ Anwarul Qulub memiliki peserta didik sebanyak 58 anak sedangkan guru yang tersedia hanya 2 guru sehingga 1 guru harus mengawasi dan membimbing 29 anak. Hal ini menjadi hambatan guru ketika pelaksanaan proses belajar mengajar di TPQ berlangsung dalam kaitannya membentuk karakter, akhlak dan budi pekerti peserta didik dikarenakan ketika guru sedang mendengarkan bacaan Al Quran anak secara satu per satu maka anak yang lainnya tidak terawasi.

Hal ini sesuai dengan temuan penelitian yang menghasilkan bahwa pendampingan guru di kelas maupun dikelompok memiliki peran atau center dalam membentuk kepribadian dan menghasilkan kemampuan peserta didik dengan berupaya mempersiapkan proses pembelajaran, mulai dari perencanaan, metode, media agar pelaksanaan pendidikan dalam berjalan sesuai dengan yang diinginkan (Anwar \& Zaenullah, 2020). Perlunya manajemen pendidikan dalam kaitannya terhadap pengembangan dan kualitas seorang guru menjadi faktor utama dalam keberhasilan program pendidikan (Argawinata, 2016).

\section{Mengatasi Hambatan Pendidikan Al Quran Dalam Upaya Membentuk Karakter Anak}

Hasil pada penelitian ini menunjukkan bahwa cara mengatasi hambatan yang ada dalam upaya mewujudkan pendidikan karakter anak pada TPQ 
Anwarul Qulub adalah anak yang tidak mendapatkan giliran membaca Al Quran dengan membiarkan anak belajar sambil bermain. Belajar sambil bermain pada TPQ Anwarul Qulub dengan metode pemberian tugas pada masing-masing anak yaitu membaca buku pada perpustakaan, menulis huruf-huruf hijaiyah pada Al Quran, menggambar kaligrafi dengan pola yang telah disediakan pada kertas gambar. Pemberian tugas kepada anak memperbolehkan anak-anak untuk bermain namun tidak diperbolehkan merugikan orang lain. Hal ini sesuai dengan karakteristik anak adalah suka bermain.

Lester D. Crow dalam bukunya Human Development and Learning dalam Khusni, ia menekankan ada tiga fase perkembangan yaitu masa childhood, maturity dan adulthood. Masa bayi (childhood) dimulai dari dalam kandungan seorang Ibu, kemudian lahir di dunia, menjadi bayi, dan masa balita hingga anak mengikuti pendidika formal (sekolah). Sedangkan maturity period merupakan proses perkembangan seseorang mengalami kedewasaan sebelum memasuki usia dewasa. Kematangan fungsi akan mempengaruhi perubahan fungsi mental (Khusni, 2018). Hal ini tentu akan menjadi problem bagi guru apabila tidak mengetahui karakteristik anak dan fase perkembangannya yang memang belum memiliki kemangatangna berfikir seperti orang dewasa. Ketekunan guru dalam mengatasi hambatan ini diiringi dengan sikap kesabaran menjadi hal penting dalam proses ini. Apabila pengetahuan guru kurang memadai sampai kontrol lingkungan sekitar yang rendah maka tidak jarang guru ada unsur "pembiaran" terhadap peserta didiknya (Sukino, 2018).

\section{Pendidikan Al Quran Sebagai Upaya Membentuk Karakter Anak}

Dalam pembahasan ini, peneliti menjelaskan bahwa TPQ Anwarul Qulub dalam upaya memberikan pendidikan karakter anak di Sidorejo Desa Sidomulyo mampu mengarah pada pengembangan dan pembentukan karakter manusia melalui program-program pendidikan didalamnya. Anak yang mendapatkan pembimbingan melalui latihan yang terus menerus dan berkelanjutan akan berdampak pada pembiasaan dan tantangan. Karakter bukan merupakan bakat ataupun bawaan lahir seorang anak, melainkan dari hasil didikan yang dilakukan secara konsisten dan terusmenerus..

Menurut Jean Piaget pendidikan yang optimal membutuhkan pengalaman yang menantang bagi si pembelajar, sehingga proses asimilasi dan akomodasi dapat menghasilkan pertumbuhan intelektual. Pendidikan karakter pada hakikatnya adalah pendidikan yang melibatkan aspek kognitif, perasaan (feeling) dan tindakan (action). Pada proses pembimbingan membaca Al Quran tersebut anak dilatih untuk bersabar untuk tidak naik tingkatan membaca Iqra' apabila belum mahir. Dengan kesabaran yang dilatih secara terus-menerus anak terbiasa untuk bertanggunggjawab atas dirinya sendiri, dilatih untuk mengendalikan emosi, dilatih untuk berusaha menggapai prestasi dengan usahanya sendiri dan bukan karena rasa empati yang dimiliki oleh guru.

Nilai-nilai karakter pada program belajar sambil bermain pada TPQ Anwarul Qulub melatih anak untuk memilki sifat kejujuran, toleransi, kehatihatian, disiplin diri, kerjasama, keberanian dan nilai demokratis. Sehingga penting bagi pendidik dalam hal ini yaitu guru TPQ menerapkan pola asuh yang sesuai dengan masing-masing anak dikarenakan setiap anak memiliki bakat dan watak yang berbeda dikarenakan unsur utama dalam karakter adalah pikiran. TPQ menitikberatkan pengajaran pada pembelajaran membaca Al Qur'an dengan muatan tambahan yang berorientasi pada pembentukan akhlak dan kepribadian islamiah.

Dalam hal ini erat kaitannya dengan pendidik sebagai komponen utama dala proses pendidikan. Temuan peneitian ini, guru memiliki peran yang sangat penting dalam kaitannya membentuk karakter anak. TPQ Anwarul Qulub memiliki keterbatasan pengajar yaitu hanya berjumlah 2 orang. Adapun metode yang digunakan dalam proses pembelajaran dengan keterbatasan guru adalah anak yang diberikan kebebasan dalam belajar sambil bermain. Secara tidak langsung, guru TPQ Anwarul Qulub dalam kaitannya 
memberikan sikap demokrasi kepada anak berkaitan erat dengan sifat responsibility atau pertanggungjawaban yang lebih menekankankan pada kewajiban-kewajiban positif pada anak.

\section{SIMPULAN}

Berdasarkan analisis data yang telah diolah maka dapat disimpukan bahwa disimpulkan bahwa TPQ Anwarul Qulub sangat berperan penting dalam membentuk karakter santri melalui pembimbingan, melatih secara terus menerus dan menasehati dalam membentuk karakter religius, mandiri, serta komunikatif. Hal ini dibuktikan dengan temuan penelitian yang menunjukkan bahwa program pendidikan yang dilaksanakan oleh TPQ Anwarul Qulub di lingkungan Sidorejo dalam upaya pendidikan karakter anak yaitu; pengajaran bacaan Al Quran secara mendalam, penghafalan surat-surat juz amma, penafsiran ayat Al Quran, hadist dan kata-kata mutiara berbahasa arab (Mahfuzhat). Hambatan dalam pelaksanaan program yaitu banyaknya jumlah anak yang ada pada TPQ Anwarul Huda dan keterbatasan guru yang mengajar. Cara mengatasi hambatan adalah anak dibiarkan belajar sambil bermain dan tetap pada pengawasan dan pembimbingan guru. Adapun saran peneliti yaitu bagi pengelola TPQ agar dapat menambah staff pengajar untuk membantu pengajar yang telah ada dalam upaya membentuk karakter anak melalui pendidikan dan pengajaran pada TPQ.

Saran dan rekomendasi bagi peneliti agar penelitian ini bisa dikembangkan dan dijadikan bahan untuk penelitian lanjutan tentang Taman Pendidikan Al Quran (TPQ) yang meliputi kegiatan lainnya didalamnya, sehingga dapat dijelaskan bahwa TPQ sebagai lembaga pendidikan non formal juga mampu memberikan dan menciptakan insan yang berkarakter dan berakhlakul karimah sesuai dengan tujuan dari pada pendidikan nasional.

\section{DAFTAR PUSTAKA}

Anwar, R. N. (2019). Motivasi Belajar Baca Tulis Al Quran Pada Ibu Rumah Tangga Di TPQ Anwarul Qulub Sidorejo. Prosiding Seminar
Nasional \& Call Paper Psikologi Pendidikan, (April), 162-166. Malang: Universitas Negeri Malang.

Anwar, R. N., Wardani, L. A., \& Vitriana, U. (2019). Pengelolaan Masjid Kampus Sebagai Pusat Pendidikan Islam dalam Pembentukan Karakter Mahasiswa di Universitas PGRI Madiun. Tarlim: Jurnal Pendidikan Agama Islam, 2(2), 135-140.

Anwar, R. N., \& Zaenullah. (2020). Perencanaan Pembelajaran Pendidikan Agama Islam Pada Anak Berkebutuhan Khusus. Jurnal Care, 8(1), 56-66.

Argawinata, A. Z. (2016). Manajemen Pendampingan Guru Untuk Meningkatkan Kompetensi Pedagogik Dan Profesional Guru-Guru Mata Pelajaran Sekolah Menengah Pertama Di Kota Bandung. Jurnal Imiah Mitra Swara Ganesha, 3(1), 1-16.

Asmani, M. J. (2012). Kiat Mengatasi Kenakalan Remaja di Sekolah. Yogyakarta: Buku Biru.

Dalmeri. (2014). Pendidikan Untuk Pengembangan Karakter (Telaah terhadap Gagasan Thomas Lickona dalam Education for Character). Al Ulum, 14(1), 269-288.

Herman. (2018). Pendidikan Karakter dalam Pandangan Islam. Qiro'ah, 1(1), 96-109. https://doi.org/10.1017/CBO9781107415324 .004

Iswan, \& Herwina. (2018). Penguatan Pendidikan Karakter Perspektif Islam Dalam Era Millenial IR. 4.0. Seminar Nasional Pendidikan Era Revolusi, 21-42. https://doi.org/10.18041/23823240/saber.2010v5n1.2536

Khusni, M. F. (2018). Fase Perkembangan Anak Dan Pola Pembinaannya Dalam Perspektif Islam. Martabat: Jurnal Perempuan Dan Anak, 2(2). https://doi.org/10.21274/martabat.2018.2.2.361382

Setiardi, D. (2017). Keluarga Sebagai Sumber Pendidikan Karakter Bagi Anak. Tarbawi: Jurnal Pendidikan Islam, 14(2), 135-146.

Sukino. (2018). Konsep Sabar Dalam Al-Quran Dan Kontekstualisasinya Dalam Tujuan Hidup Manusia Melalui Pendidikan. Jurnal Ruhama, 1(1), 63-77. 
Warsito. (2014). Peranan Budaya Dan Pendidikan

Karakter Bagi Pembangunan Bangsa.

Seminar Nasional Teknologi Pendidikan, 63-

76. Solo: Universitas Sebelas Maret. 